\title{
Ovarian modification of sexual behavior in neonatally androgenized female rats
}

\author{
KENNETH W. NIKELS \\ Kearney State College, Kearney, Nebraska 68847
}

\begin{abstract}
The influence of ovarian tenancy on the development of female sexual behavior was investigated in female rats administered 100 micrograms testosterone propionate (TP) or oil at 3 days of age and ovariectomized at birth, 60 , or 100 days of age. Sexual receptivity tests were conducted at 140 and 240 days of age. A highly significant effect of neonatally injected TP on female sexual behavior was observed, with all androgen-treated groups scoring lower than the controls. Ovarian tenancy to 100 days of age did partially counteract the effect of neonatal androgenization. No ovarian influences were detected in the oil-treated groups. Consistent relationships were observed in tests conducted at 140 and 240 days of age.
\end{abstract}

Recent evidence has suggested an important role for the prepuberal ovary in the development of female sexual behavior in the rat. Gerall. Dunlap, and Hendricks (1973) demonstrated that female rats retaining ovaries throughout prepuberal life exhibited higher levels of female sexual behavior than animals neonatally gonadectomized. In addition. male rats neonatally castrated and receiving ovarian implants showed greater female receptivity than did male subjects castrated but not receiving ovaries.

Ovarian tenancy during development has also been shown to modify the effects of neonatal androgenization. Blizard and Denef (1973) reported higher levels of female behavior in animals neonatally administered androgen when ovaries were present to 102 days of age. Additional evidence supporting an ovarian "masking effect" is provided by Hendricks and Duffy (1974), who found higher levels of female sexual behavior in androgenized females which had their ovaries intact through 20 and 60 days.

The influence of ovarian secretions during prepuberal life may vary as a function of the androgen dosage administered neonatally. Blizard. Lippman. and Chen (1975), using high and repeated dosages of TP. found that prepuberal ovaries did not "mask" the effects of neonatally administered androgen. Also, Hendricks and Duffy (1974) reported larger effects attributable to ovarian tenancy in groups receiving lower dosages of TP neonatally. The present investigation was designed to further examine the masking effect of ovarian influences on the development of sexual behavior in neontally

The author wishes to thank John Sivesind. Bill McKay, and Connie Smith for their technical assistance. Progesterone was generously supplied by Dr. Irving I. A. Tabachnick of the Schering Corporation. This research was supported in part by a grant from the Kearney State College Research Services Council and in part by the U.S. Public Health Service under Grant NS10027 administered by Dr. Shelton Hendricks, of the University of Nebraska at Omaha. who also sponsors this paper and takes full editorial responsibility for its contents. androgenized females. Sexual receptivity measures were obtained from untreated and neonatally androgenized female rats ovariectomized at various ages.

\section{METHOD}

Subjects were 98 female Harlan-Wistar rats, born in the laboratory. Within $12 \mathrm{~h}$ of birth, animals were either gonadectomized or sham operated, surgery being performed under hypothermia. Subcutaneous injections of the vehicle (corn oil) or 100 micrograms TP were administered at Day 3 (birth = Day 1). Injections were given in volumes of $.05 \mathrm{ml}$. Subjects were weaned at 21 days of age and body weights recorded at weekly intervals thereafter. Those animals not receiving neonatal operations were ovariectomized at either 60 or 100 days of age under nembutal anesthesia. All subjects were provided food and water ad lib and maintained four per cage on a 14-h-light/10-h-dart reversed cycle.

Behavior testing began at 140 days of age. Subjects received 10 micrograms estradiol benzoate (EB) $48 \mathrm{~h}$ and 500 micrograms progesterone $6 \mathrm{~h}$ prior to testing. Mounting of subjects by sexually vigorous males was observed in glass-fronted semicircular observation cages. Each test consisted of 10 mounting attempts by the male, with five such tests conducted at 5-day intervals. Three additional tests were begun at 240 days of age. Lordosis, holding, and darting responses were scored according to a system described by Gerall et al. (1973).

\section{RESULTS}

Data were randomly voided to obtain equal cell frequencies for the analysis of variance. Cell sizes were: $N=13$ for the body weight analysis. $N=12$ for the analysis of sexual behavior at 140 days of age, and $N=11$ for the Day 240 analysis.

Analysis of body weights at 90 days of age revealed significantly lower body weights in those animals with ovaries intact to 100 days. $F(2.72)=22.05, p<.01$. A significant TP effect was also observed in the analysis. those animals neonatally injected with TP being heavier than the oil-injected controls, $F(1.72)=31.88 . p<.01$.

The influence on female sexual behavior of ovarian tenancy and neonatal androgenization is depicted in 


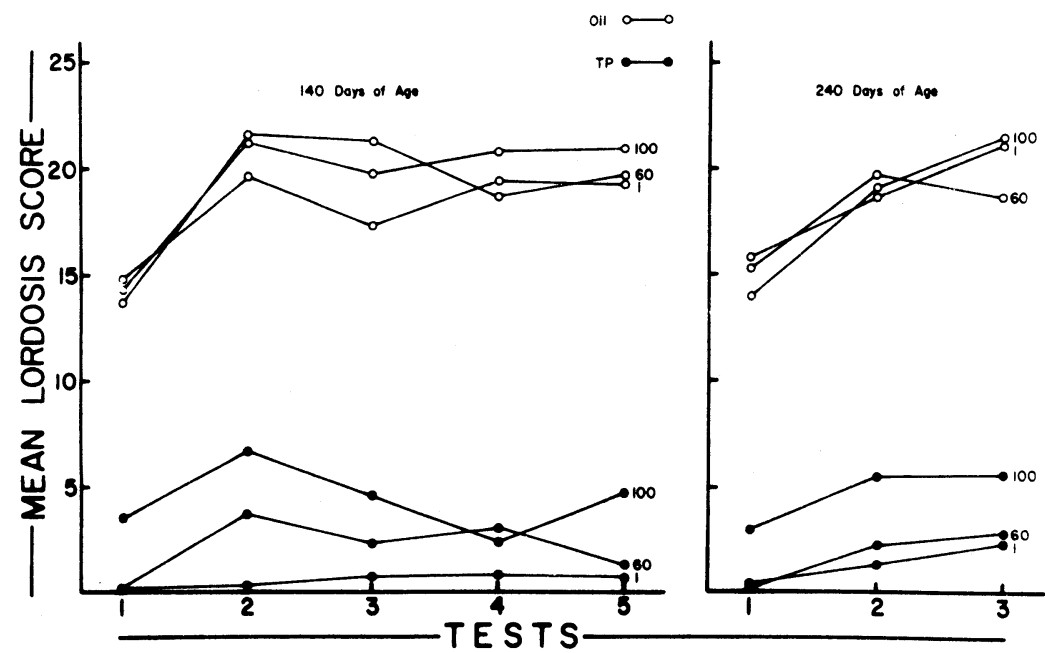

Figure 1. The influence of neonatal androgenization and ovarian tenancy on lordosis scores obtained from tests conducted at 140 and 240 days of age.
Figure 1. Mean lordosis scores were calculated for each group by summing the scores of each subject for each 10-mount test. Analysis of variance revealed that neonatal androgenization significantly reduced lordosis scores, $F(1,66)=530.93, p<.01$. The analysis also revealed a significant ovarian influence, $F(1,66)=4.36, p<.05$. Simple main effects analysis of this result indicated an ovarian influence for the neonatally androgenized subjects, $F(2,165)=11.75$, $p<.01$, but not for the oil controls $(p>.05)$. The analysis of lordosis scores also indicated a significant tests effect $(p<.01)$ and a significant interaction of tests with neonatal androgenization $(p<.05)$. For the TP-treated subjects, the tests effect was significant for the Day $60(\mathrm{p}<.05)$ and Day $100(\mathrm{p}<.05)$ groups only. Analysis of holding scores at 140 days of age revealed only a significant $\mathrm{TP}$ effect, $\mathrm{F}(1,66)=96.58$, $\mathrm{p}<.01$. Darting scores at this age were infrequent, and no reliable differences were detected by the analysis.

Lordosis scores at 240 days of age were quite simila to those at $\mathbf{1 4 0}$ days, and the analysis revealed many of the same relationships. There was a significant TP effect. $F(1,60)=175.79, p<.01$, which held across all ages of ovariectomy. There was also a significant ovarian influence, but again only for the neonatally androgenized groups, $F(2,90)=4.65, \quad p<.05$. Analysis of darting and holding scores observed at 240 days of age supported the differences found in the evaluation of lordosis score. In both cases, there was a significant TP effect. At this age, however, there were no significant ovarian influences detected on holding or darting scores. As before, there were no significant ovarian influences in the oil-treated groups.

\section{DISCUSSION}

The results of the present study offer additional support for an ovarian masking of the effects of neonatal androgenization on female sexual behavior. Ovaries present to 100 days of age were seen to partially counteract the inhibitory effects of administration of 100 microgram TP at 3 days of age. These data are generally consistent with those presented by Blizard and Denef (1973) and Hendricks and Duffy (1974). However, Hendricks and Duffy (1974) reported significant masking effects with 20 or 60 days of ovarian tenancy. In the present study, those subjects which remained intact through 60 days of age were not evaluated as being significantly different from females ovariectomized at birth. In comparing these two studies, it must be noted that Hendricks and Duffy employed lower dosages of TP, 5 microgram or 50 microgram, as compared to the 100 microgram employed in the present work. The duration of ovarian tenancy necessary to produce an observable masking effect may increase with increasing dosages of neonatally administered androgen.

\section{REFERENCES}

Blizard, D., \& Denef, C. Neonatal androgen effects on open-field activity and sexual behavior in the female rat: The modifying influence of ovarian secretions during development. Physiology and Behavior, 1973, 11, 65-69.

Blizard, D. A., Lippman, H. R., \& Chen, J. J. Sex differences in open-field behavior in the rat: The inductive and activational role of gonadal hormones. Physiology and Behavior, 1975, 14, 601-508.

Gerall, A. A., Dunlap, J. L., \& Hendricks, S. E. Effect of ovarian secretions of female behavioral potentiality in the rat. Journal of Comparative and Physiological Psychology, 1973, 82, 449-465.

Hendricks, S. E., \& Duffy, J. A. Ovarian influences on the development of sexual behavior in neonatally androgenized rats. Developmental Psychobiology, 1974, 7, 297-303.

(Received for publication October 5, 1975.) 